\title{
Some Explanations of Crime Among Four Ethnic Groups in the Netherlands
}

\author{
Marianne Junger ${ }^{1}$ and Wim Polder ${ }^{1}$
}

\begin{abstract}
Since 1950 there has been large-scale immigration to Western Europe, mainly from Muslim countries. This paper focuses on the degree of involvement in crime of ethnic minority boys as compared to indigenous boys and on the possible causes of these crime involvements. A random sample from three ethnic minority boys (Moroccans, Turks, Surinamese) was taken. A control group consisted of indigenous boys with a comparable socioeconomic background as the minority respondents. Data were gathered about self-report and recorded delinquency, family and school life, leisure time, traditionalism, migration problems, and socioeconomic status. It appears that the arrest rates among the minority youths are substantially higher than among the comparable Dutch boys. A number of explanations are considered: strain, lack of social control, cultural dissonance, and migration problems. Results show that only social control factors explain criminality within the groups, indicating that the causes of criminality among ethnic minority boys may essentially be the same as those among the indigenous boys.
\end{abstract}

KEY WORDS: ethnic minorities; social control theory; migration; the Netherlands; crime theories.

\section{INTRODUCTION}

Since the 1950 s and 1960 s there has been a large-scale migration of laborers from Muslim countries to Western Europe. Although this type of migration almost stopped after the oil crisis (1973), family reunification brought many women and children to join their husbands and fathers. As a result there are large Muslim minorities in many European countries. For

\footnotetext{
'Ministry of Justice, Research and Documentation Centre, P.O. Box 20301, 2500 EH The Hague, The Netherlands.
} 
example, it is estimated that there are about 350,000 Muslims in The Netherlands, 400,000 in the United Kingdom, 1.7 million in West Germany, 2.8 million in France, and 200,000 in Belgium (for an introduction see Gerholm and Litham, 1988).

It is generally believed that these workers will remain in their host countries, although most of them originally planned to stay only temporarily (Gerholm and Litham, 1988). The presence of the minority communities has led to speculations about future developments. For example, will these communities assimilate, or will they integrate but keep certain distinctive traits? Can we expect growing tensions between different ethnic groups?

All over Europe, Muslim immigrants confront greater social problems than most other immigrant groups (Gerholm and Litham, 1988). In addition, it appears that in many countries several ethnic minority groups are overrepresented in official criminality statistics. This has been established for the United Kingdom, France, the Netherlands, Sweden, Belgium, and Germany and in the United States (see, among others, Gould, 1969; Chambliss and Nagasawa, 1969; Nadjafi Abrandabadi, 1983; Stevens and Willis, 1979; Hindelang et al., 1979; Sampson, 1985; Block, 1985; Jäger, 1984; Craen, 1984; Albrecht, 1984, 1987; van der Hoeven, 1986). In general, blacks are overrepresented in the judicial system but Asians are underrepresented in most countries.

The assessment that ethnic minorities who immigrated to the Netherlands will most probably stay and concern about the growing numbers of ethnic minority youth entering the juvenile justice system have led the Research and Documentation Centre of the Ministry of Justice to start an investigation that focuses on two questions. The first concerns involvement in crime: What is the level of involvement in crime among youths of different ethnic minority groups? And if the involvement in crime among youths of ethnic minorities is higher than among Dutch youths, can this difference be accounted for by the relatively weak socioeconomic position of ethnic minorities in Dutch society? The second question is whether the factors related to crime are similar among ethnic minority youths and Dutch juveniles, or whether factors specific to their culture or their migrant status affect their crime rates.

To answer these questions it was decided to study select samples of youths coming from the three largest ethnic minority groups in the Netherlands: the Turks, the Surinamese, and the Moroccans. They are compared with Dutch youths from a similar socioeconomic background.

This article briefly reviews some of the main results of this study. We proceed as follows: First, the research design is introduced (Section 2). Second, a short introduction to the three ethnic minority groups in the Netherlands is given (Section 3). Third, the main results are presented (Section 4). 


\section{RESEARCH DESIGN}

In this section the main features of the research design are presented. For more information see Junger (1990a) and Junger and Polder (1991).

\subsection{The Samples}

The results bear on four samples: 182 Moroccans, 196 Turks, 206 Surinamese, and 206 Dutch boys 12-17 years old. The three ethnic minority groups were selected randomly. The Dutch sample has been selected by the interviewer in the same neighborhoods as the ethnic minority boys. It was expected that this method would produce a sample of indigenous boys with a socioeconomic background similar to that of the ethnic minorities. This group of Dutch boys is referred to as the "comparable group."

Analyses show that the ethnic minority groups probably form a representative sample of the population from which they were drawn in terms of age, urbanization, and number of respondents who have contacts with the prosecutor (Junger and Zeilstra, 1989).

As the Dutch boys are coming from the same neighborhoods as the ethnic minority boys, opportunity factors related to the physical environment and to the availability of delinquent friends are also held constant and cannot account for differences in crime.

\subsection{The Instrument}

Most data were gathered by means of structured interviews, during June/July 1985 . Information about delinquent behavior was available from the interviews as well as from data on recorded contacts with the judicial system.

\subsection{The Measurement of Delinquency}

Delinquent behavior has been defined as "those acts which can be brought to court by the public prosecutor." The self-report delinquency measures were based on 16 questions about delinquent activities asked at the end of the interview (see Appendix). Information on recorded delinquency (ever and last year) came from the police stations. We coded all police contacts for property crimes (petty theft, serious property offenses), aggression against persons, vandalism, and sexual offenses or problematic behavior (running away from home). Status offenses only seldom lead to officially registered police contacts or prosecution, except when circumstances are believed to be unusually serious.

When boys with recorded police contacts mentioned no offenses during the interview, the self-report scores have been corrected for the number of 
arrests known from the police files. In all further analyses, unless stated otherwise, these corrected measures are used.

\subsection{Validity Problems}

Analyses show that among Turkish and Moroccan respondents, the tendency to give socially desirable answers is stronger than among Surinamese and Dutch respondents. This appears to be the case for questions on self-reported delinquency data, family, school, and leisure time activities. This validity problem makes comparisons between ethnic groups on the basis of self-report information problematic. For example, it cannot be inferred from the findings whether Moroccan parents exercise more or less supervision than Dutch parents. Rather, we have to conclude that the data from the present study are not suitable for comparisons between ethnic groups. ${ }^{2}$

The restriction of the use of comparisons between ethnic groups does not exclude correlational analyses. Although mean scores are not comparable, the rank order within ethnic groups need not be strongly affected by the social desirability bias. Correspondence between self-report and police data indicates that the ordering of respondents within ethnic groups is only partially influenced by the tendency to give socially desirable answers (Junger, 1990a). The above-mentioned correction of the self-report data with police data should further reduce this influence. Consequently, correlational analyses that investigate the relations between variables are possible within each of the ethnic groups separately. For more information see Junger (1989a, 1990a).

\subsection{Analysis of the Data}

Information has been gathered on the following subjects: family relations, functioning at school, leisure time activities, delinquency of peers, values toward delinquent behavior, traditionalism, and problems related to immigration. Table I presents the main fields and indices on which information has been gathered. For each field of inquiry (e.g., family) principalcomponent analysis (PCA) was used to form relatively homogeneous groups of variables that correspond with one element of the bond to society. Both self-reported delinquency and arrest data have been used as dependent variables. In general, analyses have been performed for the total group and, also,

\footnotetext{
${ }^{2}$ Other research suggests that this validity bias has affected the results of other studies in the same way as in the present research (see, e.g., Mutsaers and Boendermaker, 1990; Baerveldt, 1990).
} 
Table 1. Main Fields Covered by the Study and Indices/Variables ${ }^{a}$

\begin{tabular}{|c|c|}
\hline Field & Indices/variables \\
\hline 1. Family & $\begin{array}{l}\text { Direct controls, family arguments, emotional bond, importance of } \\
\text { school, general evaluation of family life, violence }\end{array}$ \\
\hline 2. School variables & Conflicts, commitment, school results, being expelled from school \\
\hline 3. Leisure time & $\begin{array}{l}\text { Frequency, unconventional activities, orientation outside the family, } \\
\text { drinking by the respondent, drinking by his friends }\end{array}$ \\
\hline $\begin{array}{l}\text { 4. Values toward } \\
\text { delinquency }\end{array}$ & $\begin{array}{l}\text { Opinions on the seriousness of property crimes and aggression against } \\
\text { persons }\end{array}$ \\
\hline 5. Traditionalism & Religiosity, attitudes toward the position of women \\
\hline $\begin{array}{l}\text { 6. Problems related } \\
\text { to migration }\end{array}$ & $\begin{array}{l}\text { Knowledge of Dutch, family activities, fear for expulsion, length of } \\
\text { stay in the Netherlands, orientation toward the country of origin, } \\
\text { contacts with friends/neighbors, nationality of parent's friends, } \\
\text { expectations about leaving the Netherlands in the next } 5 \text { years }\end{array}$ \\
\hline $\begin{array}{l}\text { 7. Socioeconomic } \\
\text { status of father }\end{array}$ & SES, (un)employment \\
\hline 8. Delinquency & Self-report delinquency, arrests \\
\hline
\end{tabular}

${ }^{a}$ More information about the indices and variables is given in the Appendix.

for each ethnic group separately. Detailed information about the relations between the indices is reported by Junger (1990a).

\section{ETHNIC MINORITIES IN THE NETHERLANDS}

The largest ethnic minority groups in the Netherlands are the Turks, the Surinamese, and the Moroccans. In 1989 the number of Turks in the Netherlands was approximately 177,000 , the number of Surinamese approximately 210,000, and the number of Moroccans 140,000 (Van der Erf, 1989). These three groups are now introduced briefly.

\subsection{The Surinamese}

Surinam is a South American country, lying between British and French Guyana, and a former colony of the Netherlands.

The Surinamese do not form a homogeneous group. To start with, Surinamese have diverse ethnic backgrounds: Creoles are the descendants of former slaves brought into Surinam under the early colonial system; Hindustani came originally from India and often entered Surinam as contract laborers after slavery was abolished; there are also people from many other countries such as Indonesia and China (Campfens, 1979).

In the present study $51 \%$ of the respondents come from Hindu families, $22 \%$ describe themselves as being from Creole origin, and $25 \%$ have other ethnic backgrounds. 
Coming from a former colony, the Surinamese share some elements of Dutch culture: they often speak Dutch and learned about Dutch history and geography at school, and some of them have the same religious background (Catholic or Protestant). Many of them came at a time when the economic recession made jobs hard to find. Surinamese have, in some respects, a position between that of the Dutch citizens and that of other immigrants. In general, Surinamese speak Dutch rather well, their educational level is relatively high, their housing conditions are better, and their socioeconomic status is high in comparison with other immigrants. However, on many of these factors, they do not attain the Dutch average levels (Junger-Tas, 1985; Penninx, 1988).

\subsection{Turks and Moroccans}

In the beginning the Turks and Moroccans were recruited as workers by employers at a time of shortages on the labor market. They were recruited to do mainly unskilled (and badly paid) labor at a moment of strong economic growth. Since 1973, with growing unemployment in the Netherlands, almost no workers entered the country. But growing numbers of migrants decided to have their families come over to the Netherlands. This trend is still going on today.

As is the case for the Surinamese, neither the Turks nor the Moroccans form homogeneous groups. Moroccans in the Netherlands come from diverse regions in Morocco that differ in many respects in terms of socioeconomic development, language, and traditions. Berbers in Morocco do not always speak and/or understand Arabic. In Turkey, although $90 \%$ speak Turkish, there is also diversity in ethnic background and in cultural tradition.

Overall, Turks and Moroccans occupy, in many respects, an unfavorable position in Dutch society. In Turkish and Moroccan communities unemployment rates are high, the average income is low, the educational level is low, housing conditions are bad in comparison with those of Dutch citizens, and illiteracy rates are sometimes high. The number of men who did not have any school education differs largely within the diverse ethnic groups. Findings from a recent study show that $11 \%$ of the Turkish and $37 \%$ of the Moroccan heads of households have never been to school (Rooduijn and Latten, 1986).

\section{RESULTS}

The main results of the study are presented below. First, the sample is described in terms of socioeconomic position. Second, information on the 
Table II. Socioeconomic Status of the Father $(\%)^{a \cdot *}$

\begin{tabular}{lccccc}
\hline & $\begin{array}{c}\text { Moroccans } \\
(N=(169)\end{array}$ & $\begin{array}{c}\text { Turks } \\
(N=183)\end{array}$ & $\begin{array}{c}\text { Surinamese } \\
(N=148)\end{array}$ & $\begin{array}{c}\text { Dutch } \\
(N=182)\end{array}$ & $\begin{array}{c}\text { Dutch } \\
\text { population }^{b}\end{array}$ \\
\hline High/liberal professions & 1.8 & 3.3 & 12.2 & 12.1 & 19 \\
Employee & 1.2 & 1.6 & 8.1 & 9.9 & 20 \\
Lower employee & 2.4 & 5.5 & 18.2 & 19.2 & 16 \\
Skilled working class & 20.7 & 29.5 & 34.5 & 35.7 & 28 \\
Unskilled working class & 74.0 & 60.1 & 27.0 & 23.1 & 6 \\
\hline
\end{tabular}

${ }^{a}$ Independently of the employment status of father, information on the SES was asked for.

${ }^{b}$ Source: Reubsaet et al. (1982, p. 139).

${ }^{*} \chi^{2}=152.48122 ; \mathrm{df}=12 ; P<0.0000$.

involvement in crime is described for the four ethnic groups. Third, analyses are presented within several theoretical frameworks.

\subsection{Socioeconomic Position of the Samples}

Some information on the socioeconomic position of the boys in the four samples is provided. As mentioned above the interviewers selected Dutch boys who were living in the same blocks as the ethnic minority boys in order to match on socioeconomic background. The question is to what extent this procedure was successful. Results show that the procedure for interviewing a comparable Dutch group was successful only in part (see Tables II and III). Overall, the method that was followed succeeded in finding Dutch boys coming from the lower strata of Dutch society. Their socioeconomic position is similar to that of the Surinamese boys. But, as mentioned above, both the Surinamese and the comparable Dutch boys are better off than the Moroccan and the Turkish boys. For example, among the Dutch, $23 \%$ of the fathers are (or were) unskilled workers, among the Surinamese this is practically the same $(27 \%)$, but among the Turks and the Moroccans this is much more (respectively, 60 and $74 \%$ ). With respect to unemployment the Dutch level $(17 \%)$ is lower than the unemployment level of the ethnic minorities (32 to $43 \%$ ). This problem does not affect subsequent analyses. As information on unemployment and socioeconomic status is available, if necessary, controls

Table III. Employment Status of the father (\%)*

\begin{tabular}{lcccc}
\hline & $\begin{array}{c}\text { Moroccans } \\
(N=180)\end{array}$ & $\begin{array}{c}\text { Turks } \\
(N=193)\end{array}$ & $\begin{array}{c}\text { Surinamese } \\
(N=165)\end{array}$ & $\begin{array}{c}\text { Dutch } \\
(N=193)\end{array}$ \\
\hline Employed & 57.2 & 68.4 & 66.7 & 82.9 \\
Not employed & 42.8 & 31.6 & 33.3 & 17.1 \\
\hline${ }^{*} \chi^{2}=29.60496 ; \mathrm{df}=3 ; P<0.0000$. & & &
\end{tabular}


can be performed for the influence of these factors on delinquent behavior.

It should be noted that it is probably impossible to attain absolute equivalence between groups since the four ethnic groups differ in so many respects. As mentioned before, illiteracy among Moroccans is relatively high. It seems infeasible to select a Dutch sample in which the illiteracy rate will approximate $40 \%$. Consequently, a perfect correspondence between the various ethnic groups on socioeconomic factors will be almost impossible to achieve. $^{3}$

\subsection{Involvement in Crime}

As mentioned above, information on delinquent behavior was gathered from two sources: the respondents themselves and police files. Looking first at the self-reported figures (see Table IV), it appears that about one-half of the Moroccan and Turkish boys admitted delinquent behavior (respectively, 51 and $54 \%$ ). Among the Surinamese and the Dutch the number of boys who admitted an offense is higher (respectively, 61 and $68 \%$ ). Percentages of self-report figures corrected for police contacts are somewhat higher for each ethnic group, and differences are statistically nonsignificant (between 63 and $70 \%$ ). However, as mentioned above, self-report data are less reliable as a measure of delinquent behavior across ethnic groups and cannot be used for the purpose of comparison (for more information, see Junger, 1990a).

Consequently, we must turn to the police files to find information to compare ethnic groups in terms of delinquency. Police data can be considered

Table IV. Number of Boys Reporting Delinquent Behavior and Boys with Police

$$
\text { Contacts }(\%)
$$

\begin{tabular}{lcccc}
\hline & $\begin{array}{c}\text { Moroccans } \\
(N=182)\end{array}$ & $\begin{array}{c}\text { Turks } \\
(N=196)\end{array}$ & $\begin{array}{c}\text { Surinamese } \\
(N=206)\end{array}$ & $\begin{array}{c}\text { Dutch } \\
(N=204)\end{array}$ \\
\hline $\begin{array}{l}\text { Self-reported } \\
\quad \text { Uncorrected* }\end{array}$ & 51 & 54 & 61 & 68 \\
$\quad \begin{array}{l}\text { Corrected } \\
\text { Arrests }\end{array}$ & 63 & 64 & 64 & 70 \\
$\quad$ Ever* & 34 & 22 & 23 & 15 \\
$\quad$ Last year* & 20 & 10 & 10 & 6 \\
\hline
\end{tabular}

${ }^{*}$ Chi-square is significant $(P<0.01)$.

\footnotetext{
${ }^{3}$ The danger exists that one ends with a circular reasoning. In this case the criterion for similarity in background factors becomes the delinquency rates. One way to look at the ethnic groups and to know whether they really have similar sociodemographic characteristics would be to examine the differences in delinquericy. As long as differences in crime rates subsist, the researcher can argue that differences between ethnic groups still exist on some background variable.
} 
a relatively unbiased measure of delinquency across ethnic groups (see Junger, 1988, 1990a, b). First, it should also be noted that, as a consequence of the sampling procedure, the Dutch boys are living in the same neighborhood as the ethnic minorities. This excludes the possibility that differences in police patrol (which might be more intensive in neighborhoods with high proportions of ethnic minorities) will have influenced the findings in such a way as to produce higher arrest rates for ethnic minorities. As a result, arrest data are used to assess the involvement in crime of the four ethnic groups. In addition, up to now, no evidence of discrimination by race has been found at the level of the police registration (Junger, 1988). Therefore it seems warranted to conclude that criminal statistics probably provide an adequate index of crime.

Of all the ethnic minority groups Moroccans have the highest arrest rates $(34 \%)$, while the arrest rates of Turks and Surinamese are $10 \%$ lower (22 and $23 \%$, respectively). Comparable Dutch boys have lower rates than the ethnic minorities (namely, 15\%; see Table IV). With respect to the arrests during the preceding year, the rank order of the ethnic groups is similar. No differences have been found among ethnic groups in the type of offense or the frequency of offending (see also Junger, 1990a).

Other Dutch studies also found that ethnic minorities were generally overrepresented in police statistics (van der Hoeven, 1986; Essers and van der Laan, 1988). Recently Terlouw and Suzanne (1989) found similar results in Gouda (a small town in the Netherlands). Among the Moroccan boys (12-21 years old) 33\% have been arrested; among Dutch boys, $6 \%$. Usually, however, researchers are reticent to conclude that crime rates are indeed significantly higher because they lack an adequate comparison group. Furthermore, these studies were not based on national samples. On the basis of the present study, it can be concluded that, when a Dutch control group with a similar socioeconomic background is used, the differences in crime rates between ethnic groups do not disappear.

\subsubsection{Frequency of Arrests}

The majority of the boys with police contacts had only one contact with the police (52\%). Among the boys with police contacts, $24 \%$ had two contacts, $8 \%$ had three contacts, and $17 \%$ had four or more contacts (ever, $N=$ 182). Approximately half of the boys were arrested during the year preceding the interview. In this group, $63 \%$ were arrested only once, $22 \%$ were arrested twice, and $14 \%$ were arrested three times or more $(N=90)$. No differences were found for the overall number of arrests or the number of arrests during the last year in relation to ethnic group $(P<0.50)$. 


\subsubsection{Type of Offense}

Information from the police records was available on the type of offense. The offenses were classified as petty theft $(42 \%)$, serious property offenses $(8 \%)$, aggression against persons $(2 \%)$, vandalism $(7 \%)$, sexual offenses $(1 \%)$, problematic behavior (running away from home) (2\%), or combinations $(38 \% ; N=173)$. Among boys having police contacts, no differences among ethnic groups were found in type of offense.

\subsubsection{Specialization}

On the basis of self-report data (uncorrected measures), indications of specialization were sought. ${ }^{4}$ Factor analysis showed that the first dimension explained $21 \%$ of the variance, the second $10 \%$, and the third $8 \%$. This suggests a one-dimensional solution. Furthermore, the dimensions that appeared from the analysis could not be interpreted in a meaningful way. This finding corroborates many other studies in which no specialization has been found. For example, Dickes (1989) has tried to find dimensionality using several statistical techniques. He concludes that the best model is to scale delinquency on one single dimension (see also Hindelang et al., 1981). As a result the delinquency scales used in the present study are simply counts of the number of offenses (self-report or recorded).

The question that follows naturally from the figures presented above is how to explain the differences in crime rates. In the following sections three types of explanations are considered. Factors derived from strain theory, from control theory, and from approaches looking at the special problems of the migrants in Dutch society are related to crime among the four ethnic groups.

\subsection{Strain}

Many researchers in the Netherlands have focused upon strain theory, especially in order to explain the crime rates of ethnic minorities. The fact that $49 \%$ of the Moroccan men, $56 \%$ of the Turkish men, and $43 \%$ of the Surinamese men have a job and the others get some form of allowance/ welfare seems to support the main thesis of strain theory as an explanation of the relatively high crime rates in these groups (see Penninx, 1988).

Strain theory, as formulated by Merton (1967), assumes that everybody has been strongly socialized to pursue material success. But not everybody

${ }^{4}$ This was tried with nonlinear factor analysis (HOMALS; see Gifi, 1981) and ordinary factor analysis using several rotations techniques (oblique and orthogonal). 
has access to the same means to fulfill these wants. Some people are confronted with insufficient resources: they experience strain. Delinquency is a way out of this strain between socialization to conventional goals and restricted opportunities, because it is an alternative road to success (Merton, 1967, p. 146).

The accessibility to goals is determined by the position in the class structure. As a result the "greatest pressures toward deviation are exerted upon the lower strata" (Merton, 1967, p. 144). As people from the lower strata have limited opportunity to realize prosperity, they will relatively often choose "alternative" roads to success. Consequently, strain theory expects a strong correlation between socioeconomic status and unemployment, on the one hand, and criminal behavior, on the other hand.

To test this expectation, socioeconomic status (SES) and unemployment of the father have been related to four delinquency scales: self-report delinquency (ever and least year) and arrest rates (ever and last year). In opposition with strain theory, the results of the present study show that on the individual level, there are hardly any relations between the socioeconomic situation and delinquency. For the four groups together, the correlations between SES and four delinquency measures vary between 0.11 and -0.06 $(P>0.05)$. The correlations between unemployment and the four delinquency measures ${ }^{5}$ are nonsignificant with one exception. ${ }^{6}$ The correlations for the four ethnic groups separately are hardly any higher (see also Junger and Zeilstra, 1989; Junger, 1990a). The results are illustrated in Table V, which shows the number of boys having police contacts in the case that the father has a job and in the case that the father has no job. Whether or not the father is employed is unrelated to the occurrence of police contacts among the sons.

There is another line of reasoning within the framework of strain theory. It seems possible that not all youths, especially among the ethnic minority groups, have been equally well socialized to the success values of Dutch society. According to Merton (1967) the major socializing institutions are

Table V. Number of Boys with Police Contacts and Employment of Father $(\%)^{*}$

\begin{tabular}{lccccc}
\hline & Moroccans & Turks & Surinamese & Dutch & Total \\
\hline Father works & 31 & 21 & 26 & 13 & 22 \\
$(N)$ & $(103)$ & $(132)$ & $(110)$ & $(160)$ & $(505)$ \\
Father does not work & 36 & 25 & 15 & 24 & 26 \\
$(N)$ & $(77)$ & $(61)$ & $(55)$ & $(33)$ & $(226)$ \\
\hline
\end{tabular}

*Five chi-square tests have been performed; none are significant $(P>0.10)$.

${ }^{5}$ Self-report delinquency ever and last year, arrests ever and last year.

${ }^{6}$ Arrests last year * unemployment: $r=-0.09, P<0.05, N=749$. 
the family, the school, and the workplace. In principle, families do not generate strain. Parents will not produce strain because "family largely transmits that portion of the culture accessible to the social stratum and groups in which the parents find themselves" (Merton, 1967, p. 158). This means that, overall, family influences are not very important as a cause of crime. But "schools are of course the official agency for the passing on of the prevailing values, with a larger proportion of the textbooks used in city schools implying explicitly that education leads to intelligence and consequently to job and money success" (Merton, 1967, p. 137). It could be argued that social position in itself is insufficient to locate those who experience strain. To experience strain it is necessary to combine restricted opportunities with successful socialization to the conventional success values of our society. The socialization process to these values takes place mainly at school.

In the present article it is assumed that a strong bond to school is indicative of, and will be associated with, a successful socialization to the success values of our society. Accordingly, the relation SES-delinquency will exist only among the pupils functioning well at school. Children of a low SES and a strong bond to school will be both attached to conventional success goals and handicapped in attaining material success. As a result they will experience strain and are likely to have high delinquency rates. Consequently, among pupils of a low social economic status, a strong bond with school will lead to more delinquent behavior rather than less, as social control behavior predicts. This expectation has been tested using log-linear analysis. In this analysis the relation between delinquency, on the one hand, and unemployment/SES, on the other hand, is studied after controlling for school integration and ethnic groups. The main conclusion is that there is no relation between SES or unemployment and delinquent behavior, after controlling for ethnic groups and the bond to school (see the Appendix, Table AII).

These results are illustrated in Table VI. ${ }^{7}$ The relation between the bond to school and delinquency is presented for various levels of SES and unemployment. The data do not support the prediction of strain theory. Among children from families with a low SES or with unemployed fathers, a strong bond to school protects against delinquency instead of promoting it. Analyses with recorded delinquency produce similar results (see Junger, 1990a). The results show that the relation between school integration and delinquent behavior holds within each category of SES and employment

\footnotetext{
${ }^{7}$ In Table VI, due to small numbers, it was not possible to split the figures according to ethnic group. However, the anajysis presented in the Appendix (Table AII) does control for ethnic group.
} 
Table VI. Percentage of Respondents who Committed at Least One Offense (Self-Report) in Relation to School Integration According to SES and Employment Status of the Father and Relation with Self-Report Delinquency $(\gamma \text { and } r)^{a}$

\begin{tabular}{lcccccc}
\hline & \multicolumn{3}{c}{ School integration } & & \\
\cline { 2 - 3 } & High & Average & Low & $\gamma$ & $r$ \\
\hline SES & & & & & \\
High & 44 & 67 & 100 & 76 & $0.34^{* * *}$ \\
$\quad(N)$ & $(9)$ & $(58)$ & $(15)$ & & \\
Lower employees & 64 & 64 & 100 & 44 & $0.19^{*}$ \\
$\quad(N)$ & $(11)$ & $(52)$ & $(9)$ & & \\
Skilled workers & 58 & 63 & 95 & 44 & $0.18^{* *}$ \\
$\quad(N)$ & $(24)$ & $(150)$ & $(21)$ & & \\
Unskilled workers & 29 & 65 & 90 & 65 & $0.29^{* *}$ \\
$\quad(N)$ & $(41)$ & $(229)$ & $(19)$ & & \\
Employment & & & & & \\
$\quad$ Yes & 41 & 67 & 94 & 62 & $0.28^{* * *}$ \\
$\quad(N)$ & $(71)$ & $(354)$ & $(51)$ & & \\
No & 50 & 60 & 100 & 40 & $0.25^{* * *}$ \\
$\quad(N)$ & $(18)$ & $(163)$ & $(23)$ & & \\
\hline
\end{tabular}

${ }^{a}$ The index school integration is computed as the weighted sum of the four school indices, resulting from the regression analyses with self-report criminality as the dependent variable.

${ }^{b}$ Not included: retired fathers.

* $P<0.05$.

** $P<0.01$.

*** $P<0.001$.

status. Boys who are functioning well in school are less delinquent than those who function poorly, a result that is in agreement with social control theory, as shown below.

\subsection{Social Control}

Control theory assumes that people always "want more" and that, in contrast with most other theories of crime causation, no special motivation is necessary to pursue short-term pleasures or to act out of self-interest. In that sense, everybody is motivated to commit crimes, at all levels of the social structure (Gottfredson and Hirschi, 1990).

Consequently, the central question in order to explain delinquency according to Hirschi is not "why do they do it" but "why don't we do it" (Hirschi, 1969, p. 34). The answer is that the quality of the social bond is not equally strong for all people. This bond acts as a control mechanism and as a brake to inhibit our deviant tendencies.

In 1969 Hirschi presented his operationalization of social control theory. Although social control applies to all forms of crimes and all types of criminals, Hirschi's (1969) operationalization focused on juveniles. The 
bond to society has several components. Attachment to significant others: youths usually have strong effective ties with their parents, teachers, and friends. Commitment to conventional subsystems such as school and work: this is the "rational component" of the bond-a desire to conform and to invest in the future in a conforming way (Hirschi, 1969, p. 20). Involvement in conventional activities: this is the way youths function in their family, at school, or at work. To the extent that ties to conventional others are weak, commitment to society is low, and juveniles function inadequately in diverse social institutions, delinquency will not be restrained. Beliefs in conventional values: social control theory claims that there is a single value system, with respect to delinquency, condemning delinquent behavior. But although this value system is shared by people, not everybody feels the same commitment to these values. The lack of beliefs prohibiting delinquent behavior probably has an independent effect on the probability of committing delinquent acts.

In this study, attachment, involvement, and commitment have been operationalized within the fields in which children function: family (six variables), school (four variables), leisure time activities (five variables), and values toward delinquency (one variable). These variables and indices have been related to delinquent behavior in a multiple regression analysis (the various variables described in Table I). The results show that all correlations are statistically significant. Values are related positively to delinquency for each ethnic group $(0.33<r<0.46)$. The six family indices are also related to self-reported delinquent behavior $(0.33<R<0.46)$ and the three school variables are related to the occurrence of delinquency $(0.42<R<0.51)$. Finally, the five variables and indices measuring leisure time activities are also related relatively strongly to delinquency $(0.38<R<0.54)$. The total multiple correlations (of all 16 variables/indices taken together) vary between 0.61 and 0.70 (see Table VII).

These results corroborate the expectations of social control theory. As hypothesized, youths with strong bonds to their family, to school, and to conventional values, and who do not participate in unconventional activities, are likely to have low delinquency rates. Youths with weak bonds to their family, to school, and to conventional values, and who often participate in unconventional activities are likely to have high delinquency rates. These findings hold for each ethnic group. The results are similar when analyses are repeated with arrests as the dependent variable (see Tables VII and AI).

\subsection{Culture, Migration, and Delinquency}

Several approaches suggest that the relative high crime rates among ethnic minority groups are the result of particular problems that originate 
Table VII. Social Bond Factors and Self-Reported Delinquency: Correlations and Multiple Correlation Coefficients ${ }^{a}$

\begin{tabular}{lcccc}
\hline \multicolumn{1}{c}{ Bond factor } & Moroccans & Turks & Surinamese & Dutch \\
\hline Values (1 variable) & $0.34^{*}$ & $0.37^{*}$ & $0.33^{*}$ & $0.46^{*}$ \\
Family (6 variables) & $0.46^{*}$ & $0.33^{*}$ & $0.37^{*}$ & $0.44^{*}$ \\
School (4 variables) & $0.44^{*}$ & $0.44^{*}$ & $0.42^{*}$ & $0.51^{*}$ \\
Leisure time (5 variables) & $0.39^{*}$ & $0.38^{*}$ & $0.54^{*}$ & $0.54^{*}$ \\
Total $R$ (16 variables) & $0.67^{*}$ & $0.61^{*}$ & $0.67^{*}$ & $0.70^{*}$ \\
Expl. variance (\%) & 45 & 37 & 45 & 49 \\
$N$ Total & 182 & 196 & 206 & $204^{b}$ \\
\hline
\end{tabular}

${ }^{a}$ See Table I for the variables entered at each step.

${ }^{b} N$ varies slightly according to missing values.

${ }^{*} P<0.05$.

from the fact that they come from a different cultural background and from the migration experience. At least three approaches can be discerned. In this paper I discuss briefly the cultural dissonance approach, the traditionalism approach, and the view that problems resulting from migration might explain the crime rates among ethnic minority groups.

\subsubsection{Traditionalism}

It has been suggested that some ethnic minority boys are "modernized" when they come into contact with Dutch culture. As a consequence they will lose the bond to their traditional culture. This leads to conflicts with the parents, who will usually be (and remain) very traditional. The main idea seems to be that the loss of the bond to the traditional culture might lead to deviant behavior. Integration in one culture seems to preclude integration in the other. For example, Werdmölder (1985) mentions that the marginal Moroccan boys he studied want to go out to discotheques, meet (Dutch) girls, and wear clothes of the right brand. In other words, they want to participate in the Dutch modern youth culture. As a consequence, integration in the Dutch society leads to a loss of traditional bonds, which then will lead to higher delinquency rates.

However, alternatively it could also be argued that the less traditional families are, the more easily they will be able to participate in Dutch society. As a result less traditional boys will be less delinquent.

Religiosity and attitudes toward the position of women are two concepts that are often referred to when cultural differences are studied (see, e.g., Van den Berg-Eldering, 1981; Risvanoglu-Bilgin et al., 1986). In the present research four indicators have been chosen to measure the bonding of boys to traditional values: their attitudes toward women, their religiosity, the number of children in the family, and urbanization in the country of origin. 
Overall, these variables are unrelated to the occurrence of delinquency. ${ }^{8}$ Religion appears to be the only one of these factors related to delinquency. It is a rather weak relation ( $r$ varies around -0.20 ). Higher levels of religiosity are related to relatively low delinquency rates. This relation is found among all ethnic groups except the Turks.

\subsubsection{Adjustment Problems Resulting from Migration}

Several problems can result from migration when people have to begin a new life in a foreign country. They will eventually miss the support of a social network and live in relative isolation (Ferrier, 1988). Problems can occur because migrants do not speak Dutch sufficiently well to integrate in Dutch society. Finally, problems surrounding the legal position in the Netherlands have been mentioned as an obstacle to a proper integration. The relatively weak legal position of the Moroccans and Turks in the Netherlands can lead to difficulties in the assimilation process into Dutch society.

Many of these problems have been mentioned in the literature in connection to the Turks and Moroccans. In many respects they probably do not concern Surinamese to the same extent (see Section 3).

In our study a number of indices/variables measure the extent to which the respondents and/or their parents might encounter relatively severe difficulties in Dutch society as a result of the fact that they are migrants: knowledge of Dutch, family activities, fear for expulsion, length of stay in the Netherlands, orientation toward the country of origin, contacts with friends/neighbors, the nationality of parent's friends, and expectations about leaving the Netherlands in the next 5 years (see also the Appendix).

Practically none of these indices/variables are related in any systematic way to criminality (self-reported or recorded delinquency). Although it is plausible that people need to adjust to a new country, and migration can lead to problems of adaptation, the present research provides no evidence that these problems are related to criminal behavior.

\subsubsection{Cultural Dissonance and Delinquency}

Youths of ethnic minorities have been described as "living between two cultures" (Tennekes, 1989). According to Budike (1988) most of them find

\footnotetext{
${ }^{8}$ There are some exceptions: the number of children in families has no relation to delinquency among the ethnic minorities but does relate to crime among Dutch boys. The higher the number of children, the higher the number of recorded police contacts. In addition, there is a relation between urbanization level in the country of origin and delinquency among the Surinamese. This relation was found for self-reported delinquency (last year and ever $=-0.20$ ) but not for the arrest data. A higher urbanization level is associated with relative more selfreported delinquency.
} 
themselves in a situation of "permanent intercultural conflict." These statements are illustrative of the culture dissonance approach. According to this approach youths who are involved in two cultures can experience problems when these two cultures have-partly-different value systems and/or prescribe different behavior in particular situations. For the person placed in such a position, this can have several effects. In principle, these effects can be positive or negative. Dependent on the perception of the subject, cultural dissonance might lead to "conflicts, conformity, deviance, growth, and change" (see Chau, 1989). The outcome can be positive when the differences are stimulating. But, according to most authors, cultural dissonance is a situation of conflict which is painful and confusing (see Maliepaard, 1985, pp. 66-69). The Scientific Council of Government Policy (WRR, 1979) has described the problems of identity which can occur as a result of cultural dissonance.

\begin{abstract}
Growing up in two worlds with a different social status in each of them, with different opinions, with little understanding for each other, and even sometimes hostile towards each other but that both demand loyalty, poses for this generation [children from migrants] important identity problems, and engenders a lack of normalcy in consequence. (p. 14)
\end{abstract}

It is not entirely clear how the process actually works. First, integration in a community might be seen as relatively constant over time and over persons. Moroccans will always be integrated to a large extent in their own community and, to a certain degree, in Dutch society. Consequently, one might assume that every Moroccan and Turkish boy coming from anotherIslamic - cultural background would experience cultural dissonance. However, this model cannot explain why some members of ethnic minorities commit crimes and others do not.

Second, if integration in both communities varies, it seems plausible that cultural dissonance is possible only when there is a relatively strong integration in both cultures because otherwise the feelings of dissonance will not occur. Consequently, a strong integration in two different cultures could lead to problems like delinquency.

The conclusion that traditionalism or problems resulting from migration do not affect delinquency does not, in itself, support the cultural dissonance approach. However, proponents of the cultural dissonance approach might argue that this assessment is not a dismissal of their thesis. The approach applies to boys who are strongly influenced by both communities, because only in this situation cultural dissonance will occur. Consequently, one should look for an interaction effect among integration in the Dutch society, bonds to traditionalism, and delinquency. If this line of reasoning is correct, it might be expected that boys who are strongly integrated in school (an institution functioning according to Dutch standards and 
representative of Dutch values) but who, at the same time, have traditional attitudes toward the position of women in society, will experience the highest levels of dissonance. Accordingly they should have higher crime rates than other boys. This hypothesis is tested in Table VIII. The mean delinquency levels are broken down for school integration and attitudes toward the position of women. An analysis of variance is performed for each ethnic group.

The data presented in Table VIII confirm what was mentioned above. School integration is related quite strongly to delinquent behavior. When children are well integrated in school, they commit fewer delinquent acts than less integrated children. This holds for each ethnic group and for each level of traditionalism. At the high level of school integration the mean selfreport delinquency level varies between 0.40 and 1.17. At the low level of school integration the mean self-report delinquency varies between 1.33 and 4.67 .

The attitudes toward the position of women are unrelated to delinquency. This holds also for the three ethnic groups.

Finally, the interaction terms of the three analyses are statistically nonsignificant. At each level of the index "position of women," the relation between school integration and delinquency is unaltered. Among the youths

Table VIII. School Integration, Attitudes Toward the Position of Women, ${ }^{a}$ and Delinquency: Mean Self-Report Delinquency Scores for Three Ethnic Groups and Statistics

\begin{tabular}{lccc}
\hline & \multicolumn{3}{c}{ School integration } \\
\cline { 2 - 4 } \multicolumn{1}{c}{ Position of women } & High & Average & Low \\
\hline 1. Moroccans & & & \\
Traditional & 0.40 & 1.06 & 1.33 \\
$\quad$ Average & 1.05 & 1.07 & 1.95 \\
$\quad$ Not traditional & 0.82 & 0.91 & 2.43 \\
2. Turks & & & \\
Traditional & 0.88 & 0.78 & 2.20 \\
$\quad$ Average & 0.68 & 1.47 & 2.31 \\
Not traditional & 0.50 & 1.00 & 3.00 \\
3. Surinamese & & & \\
Traditional & 0.75 & 1.17 & 2.71 \\
$\quad$ Average & 1.17 & 1.56 & 4.67 \\
$\quad$ Not traditional & 0.81 & 1.65 & 2.38 \\
\hline \multicolumn{1}{l}{ Main effect } & School & Position of women & Interaction \\
\hline Moroccans & $F=9.4 ; P=0.00$ & $F=0.41 ; P=0.66$ & $F=0.7 ; P=0.56$ \\
Turks & $F=16.2 ; P=0.00$ & $F=0.25 ; P=0.78$ & $F=1.0 ; P=0.39$ \\
Surinamese & $F=15.6 ; P=0.00$ & $F=2.26 ; P=0.11$ & $F=2.2 ; P=0.07$ \\
\hline
\end{tabular}

${ }^{a}$ Women should stay at home (traditional) or go to school (nontraditional). 
most likely to be in a position of cultural dissonance (namely, well integrated in school and with traditional attitudes toward women), the mean delinquency rate is relatively low rather than high. This means that, in contrast with cultural dissonance theory, there is no interaction effect of school and "position of women." These analyses were repeated for recorded delinquency and for religion as a measure for traditionalism. The results are similar.

An alternative possibility is that those who have lost the bond to their own community, but are integrated in Dutch society, will have higher rates of delinquency. No support is found for this suggestion either. At each level of school integration, attitudes toward the position of women are not related to delinquency.

\section{SUMMARY AND DISCUSSION}

The aim of this study is to answer two questions. The first question concerns the involvement in crime among ethnic minority juveniles. Arrest rates have been used to determine the degree of involvement in crime of the respondents, since criminal records proved to be a reliable indicator of the participation in crime among the four ethnic groups. From the arrest data it appears that ethnic minority youths have higher crime rates than Dutch youths, regardless of whether they are compared with Dutch youths of a similar socioeconomic background or with a random sample of Dutch youths. Of all the ethnic minority groups, Moroccans have the highest arrest rates, namely, $34 \%$. They are followed by the Surinamese, with $23 \%$, and the Turks, with $22 \%$. The comparable Dutch youths have a still lower arrest rate, namely $15 \%$; however, Dutch youths from a random sample have an arrest rate of $10 \%$.

It is noteworthy that the Dutch boys have been selected living in the same block as the ethnic minority boys, so that the opportunities to commit crimes (for example, proximity to shops) are similar for both the Dutch and the ethnic minority boys. In addition, this form of matching also controls for the differences that might exist in police patrolling between neighborhoods. Consequently, the difference between the Dutch and the ethnic minority youths cannot result from either differences in the opportunity to commit crime or differences in police patrolling.

Some authors have argued that differences in delinquency rates between ethnic groups will disappear when socioeconomic conditions are taken into account (Albrecht, 1984, 1987; van der Hoeven, 1986). Apparently, even after controlling for socioeconomic background, differences in involvement in crime between ethnic groups persist.

The differences in crime between ethnic groups are simply differences in the level of participation in crime: no differences have been found among 
ethnic groups as to type of offense or frequency of offending. This supports the thesis of Gottfredson and Hirschi (1990) that the differences that appear between groups are differences in involvement and not in frequency or type of offense.

The second purpose of the study was to investigate whether the causes of crime are similar among the youths or whether factors specific to the culture or the migrant status of the minority groups affect their crime rates. Several theoretical frameworks have been considered.

\subsection{Strain Theory}

A central aspect of strain theory is that there is a relation between someone's place in the social structure and delinquent behavior. As a result, strain theory predicts a relation between socioeconomic status and unemployment, on the one hand, and delinquency, on the other hand. This relation has not been found. The results show that there are systematic relations between socioeconomic position and delinquent behavior within the ethnic groups.

Another possibility of assessing which people are strained is to look at the combination of the bond to school and SES. The expectation is, according to strain theory, that children of a low SES (or with fathers without a job) and strongly attached to school will be seriously handicapped in attaining conventional success goals. This group should feel strained and, accordingly, have high delinquency rates. Again, this prediction could not be confirmed by the data. Youths having a strong bond to school are less delinquent than those having a weak bond. This holds at each level of SES and for fathers with or without a job.

\subsection{Social Control Theory}

According to social control theory the strength of the social bond will determine the likelihood of delinquent behavior. In the present study the bond to society has been measured over the various fields in which children develop: family, school, leisure time, and peers. Overall, the findings of the present study support social control theory. As hypothesized, youths with strong bonds to their family, to school, and to conventional values, and who do not participate in unconventional activities, are likely to have relatively low delinquency rates. These findings hold for each ethnic group.

\subsubsection{Problems Resulting from Migration}

The results of this research show that, although migration places people before problems of adaptation, there is no evidence that it leads to delinquent 
behavior. Delinquent behavior is unrelated to the number of social contacts of the parents, the knowledge and use of the Dutch language, or the fear of expulsion from the Netherlands.

\subsubsection{The Traditionalism Approach}

Two possible relations of traditionalism with crime might be considered. The first possibility is that the loss of the bond with traditional values has negative effects for the ethnic minority youths and might result in higher crime rates. The second possibility is that less traditionalism leads to better integration in the Netherlands. This could result in lower crime rates. The data do not support either of these expectations. All the indices/variables referring to traditionalism are unrelated to delinquency.

There is one exception: religiosity has a rather weak relation with delinquent behavior. However, religiosity cannot be considered as a factor with a special relevance for ethnic minorities. The fact that this relation also holds for Dutch youths means that its importance is not restricted to ethnic minorities.

\subsubsection{Implications for the Cultural Dissonance}

Overall the findings do not provide evidence to support the cultural dissonance approach. The fact that traditionalism is unrelated to delinquency is contrary to cultural dissonance prediction. It has also been investigated whether the experience of conflict among youths having strong bonds with Dutch society (namely, with school) and their own traditional culture will lead to relatively high delinquency rates. The findings do not support this thesis.

It is worth mentioning that several authors found that the marginalization process of the Moroccan youths began in Morocco instead of the Netherlands. The majority of the marginal Moroccan youths (in Holland) were deviant already in their country of origin: they were truants, they used alcohol or drugs, and some had already police contacts. This finding suggests that the same factors that cause delinquent behavior in the Netherlands were already operating in Morocco. This is in contradiction to the expectation of the cultural dissonance approach, since it seems unlikely that cultural dissonance could start in Morocco (Werdmölder, 1986; Kaufman and Verbraek, 1986).

Finally, it is noteworthy that Chinese children do share the problems of migration and culture conflict. However, in most countries they have similar or lower crime rates than natives (see, e.g., Junger, 1989b). In the Netherlands the Chinese children arrived during the seventies as a result of family reunion, just as the Turkish and Moroccan children. Consequently, 
they should also experience cultural dissonance. However, they seem to function relatively well at school. It has been suggested that the strong family ties among Chinese are responsible for these good results at school.

The findings suggest that the problems resulting from migration and differences in cultural background in relation to criminality have been largely overstated.

It has been argued that social control theory is a typically "middleclass" theory, which is based on middle-class values and was developed by middle-class social scientists (Bruinsma, 1990). Consequently, applying social control theory to Islamic and Surinamese youths who are largely lower class and who come from non-Western countries could provide a strong confirmation of the theory. The findings of the present study show that social control theory passes this test.

\section{APPENDIX}

The following indices/variables are used in this article.

\section{Family Variables}

Direct Controls. Questions were asked about the amount of surveillance of the parents, the feeling of the boys whether they "could do whatever they liked," and whether the parents checked if they did their homework.

Family Arguments. Questions were asked about the amount of arguments in the family.

Violence. This index measures the amount of violence in the family. Questions were asked whether brothers, sisters, and the respondent were beaten.

Emotional Bond. To measure the emotional bond between parents and children, boys were asked if they spoke about their problems with their parents and if they did get compliments when they did something well.

Importance of School. This index measures the degree to which parents think (according to the boy) that school(success) is important.

General Evaluation of the Family Life. Five questions were asked about the respondent's satisfaction with family life.

\section{School Variables}

Conflicts. This index measures the number of conflicts with teachers.

Commitment. This has been measured by asking questions about the enthusiasm of the respondent for school, the importance he attaches to school success, and the significance of the opinion of teachers and of good school results. 
School Results. This index is based on two questions about repeating classes and the number of insufficient marks.

Being Expelled from School. One question was asked about expulsion from school.

\section{Leisure Time Variables}

Frequency. The frequency index measures the amount of time spent outside the home.

Unconventional Activities. This index counts the number of unconventional activities the boys engage in regularly. These activities are going to bars, discotheques, or youth clubs, going to the center of town, or hanging around.

Orientation. Questions have been asked about their favorite place. Some boys answered that they like to be at home. Others mention that they would rather be with friends. The "orientation" index measures the degree to which children are oriented toward the family or, alternatively, toward going out with friends and activities outside the home.

Drinking. Respondents were asked how much alcohol they would drink, and how much alcohol their friends would drink, when going out.

\section{Culture, Migration, and Delinquency}

Religiosity. The index is composed of questions about going to church (or the mosque/temple), praying, and following other rules concerning food or fasting.

Attitudes Toward the Position of Women. This index reflects the attitudes of respondents or the importance of girls going to school and the possibility of their having boyfriends. Questions were also asked about who does the shopping (as traditional Islamic women are not supposed to leave their homes on their own).

Number of Children in the Family, Urbanization in Country of Origin and Knowledge of Dutch. Several questions have been asked about the knowledge of Dutch, the use of the Dutch language at home and at school, and the importance parents attach to the knowledge of Dutch.

Fanily Activities. Questions were asked about activities of the family with other family members (including members of the extended family).

Fear of Expulsion. The boys were asked whether they feared being sent back to their country of origin by their parents or by the police.

Length of Stay in the Netherlands. The degree of orientation to their own community in the Netherlands or the country of origin was measured 
by the following questions: nationality of parent's friends, contacts with friends/neighbors, frequency of visits to the country of origin, expectation of leaving the Netherlands, and saving to return.

\section{Bond to Conventional Values}

To measure the bond to conventional values questions have been asked about the seriousness of several crimes. These questions concerned property crimes and aggression against persons.

\section{Socioeconomic Status (see Table AII)}

Socioeconomic status of the father was divided into five categories (from high to low): high/liberal professions, employee, lower employee, skilled working class, and unskilled working class. In addition, respondents were asked whether or not their father had a job.

\section{Delinquency Variables}

1. Did you ever not pay (enough) for public transport?

2. Did you ever steal anything at school?

3. Did you ever steal anything from a car?

4. Did you ever steal a bicycle/motorcycle?

5. Did you ever steal something at home?

6. Did you ever do some "joy-riding"?

7. Did you ever sell drugs?

8. Did you ever buy something which was probably stolen?

9. Did you ever threaten to assault anybody using a knife or a gun?

10. Did you ever actually beat or hit anybody?

11. Do you carry a gun?

12. Did you ever force a girl to have sex?

13. Did you ever destroy something which did not belong to you?

In shops, did you ever ...

14. Steal anything worth 10 guilders $( \pm \$ 5)$ or less?

15. Steal anything worth between 10 guilders $( \pm \$ 5)$ and 100 guilders $( \pm \$ 50)$ ?

16. Steal anything worth more than 100 guilders $( \pm \$ 50)$ guilders? 
Table AI. Social Bond Factors and Officially Registered Delinquency (Ever): Correlations and Multiple Correlation Coefficients ${ }^{a}$

\begin{tabular}{lllll}
\hline \multicolumn{1}{c}{ Bond factor } & Moroccans & Turks & Surinamese & Dutch \\
\hline Values ( I variable) & 0.09 & $0.12^{*}$ & $0.17^{*}$ & $0.28^{* * *}$ \\
Family (6 variables) & $0.31^{* *}$ & $0.30^{* * *}$ & $0.27^{* * *}$ & $0.44^{* * *}$ \\
School (4 variables) & $0.46^{* * *}$ & $0.30^{* *}$ & $0.42^{* * *}$ & $0.29^{* *}$ \\
Leisure time (5 variables) & $0.34^{* * *}$ & 0.19 & $0.41^{* * *}$ & $0.28^{* *}$ \\
Total $R$ (16 variables) & $0.56^{* * *}$ & $0.44^{* * *}$ & $0.51^{* * *}$ & $0.57^{* * *}$ \\
$N$ total & 182 & 196 & 206 & $204^{b}$ \\
\hline
\end{tabular}

${ }^{a}$ See Table I for the variables entered at each step.

${ }^{b} N$ varies slightly according to missing values.

$* p<0.05$.

** $P<0.01$.

*** $P<0,001$

Table AII. The Relation Between Delinquency and Unemployment/SES, Controlling for School Integration and Ethnic Groups: Models and Ratio Chi-Square Statistics of Log-Linear Analysis

\begin{tabular}{ccc}
\hline Model 1 & Model 2 \\
\hline & Self-report \\
Ethnic group $*$ school integration & Model 1 and delinquency * unemployment
\end{tabular}

Ethnic group * unemployment

Ethnic group $*$ delinquency

Delinquency $*$ school

(1) $\chi^{2}=30.5, \mathrm{df}=26, P=0.25$

(2) $\chi^{2}=30.2, \mathrm{df}=25, P=0.22$

Difference $\chi^{2}(1)-\chi^{2}(2)=0.3, \mathrm{df}=1, P=0.80$

Ethnic group * school integration

Model 1 and delinquency * SES

Ethnic group * SES

Ethnic group * delinquency

Delinquency $*$ school

(1) $\chi^{2}=71.8, \mathrm{df}=66, P=0.29$

(2) $\chi^{2}=69.5, \mathrm{df}=63, P=0.27$

Difference $\chi^{2}(1)-\chi^{2}(2)=2.3, \mathrm{df}=3, P=0.50$

Arrests

Ethnic group * school integration

Model 1 and delinquency $*$ unemployment

Ethnic group $*$ unemployment

Ethnic group $*$ delinquency

Delinquency $*$ school

(1) $\chi^{2}=28.9, \mathrm{df}=26, P=0.31$

(2) $\chi^{2}=28.9, \mathrm{~d} \mathbf{f}=25, P=0.27$

Difference $\chi^{2}(1)-\chi^{2}(2)=0, \mathrm{~d} f=1, P=1$

Ethnic group * school integration

Model 1 and delinquency * SES

Ethnic group $*$ SES

Ethnic group $*$ delinquency

Delinquency $*$ school

(1) $\chi^{2}=58.3, \mathrm{df}=66, P=0.74$

(2) $\chi^{2}=54.2, \mathrm{df}=63, P=0.78$

Difference $\chi^{2}(1)-\chi^{2}(2)=4.1, \mathrm{df}=3, P=0.20$ 


\section{REFERENCES}

Albrecht, H. J. (1984). Problems of policing ethnic minorities in the Federal Republic of Germany. In Brown, J. (ed.), Policing and Social Policy; The Cranfield-Wolfson Colloquium on Multi-ethnic Areas in Europe, Police Review Publication, London.

Albrecht, H. J. (1987). Foreign minorities and the criminal justice system in the Federal Republic of Germany. Howard J. Crim. Just. 6: 272-286.

Baerveldt, C. (1990). School en Delinquency (School and Delinquency), Gouda Quint, Arnhem. Block, C. R. (1985). Race/ethnicity and patterns of Chicago homicide 1965-1981. Crime Delinq. 31: $104-116$.

Bruinsma, G. J. N. (1990). De schaduwzijde van de sociale controle theorie (The dark side of social control theory). In Zwanenburg, M. A., and Smit, A. M. G. (eds.), Kleine criminaliteit en overheidsbeleid, Gouda Quint bv., Arnhem.

Budike, F. (1988). Reclassering en de tweede generatie allochtonen (Probation and the Second Generation Immigrants), Nederlandss Federatie voor Reclasseringsinstellingen, Den Bosch.

Campfens, H. (1979). The Integration of Ethno-cultural Minorities: A Pluralist Approach. The Netherlands and Canada: A Comparative Analysis of Policy and Programme, Ministry of Cultural Affairs, Recreation and Social Welfare, The Hague.

Chambliss, W. J., and Nagasawa, R. H. (1969). On the validity of official statistics: A comparative study of white, black and Japanese high-school boys. J. Res. Crime Delinq. 6: 71-83.

Chau, K. L. (1989). Socio-cultural dissonance among ethnic minority populations. Sac. Casework J. Contemp. Soc. Work 70: 224-230.

Craen, A. (1984). Policing and social policy in the multi-ethnic area of Genk. In Brown, J. (ed.), Policing and Social Policy; The Cranfield-Wolfson Colloquium on Multi-ethnic Areas in Europe, Police Review Publication, London.

Dickes, P. (1989). What kind of homogeneity for self-report delinquency items? In Klein, M. (ed.), Cross-National Research in Self-Reported Crime and Delinquency, Kluwer Academic, Dordrecht, pp. 249-267.

Essers, A. A. M., and van der Laan, P. H. (1988). Jeugd en Justitie (Youth and Justice), WODC, Ministerie van Justitie, Den Haag.

Ferrier, J. (1988). Casa Migrantes en Opo Fre Bakka (Casa Migrantes and Opo Fre Bakka). Tijdschrift Jeugdhulpverlening 16: 224-231.

Gerholm, T., and Litham, Y. G. (1988). The institutionalisation of Islam in the Netherlands, 1961-1986 (Introduction). In Gerholm, T., and Litham, Y. G. (eds.), The New Islamic Presence in Western Europe, Mansell, London.

Gifi, A. (1981). Non-linear Multi-variate Analysis, Department of Data Theory, University of Leiden, Leiden.

Gottfredson, M. R., and Hirschi, T. (1990). A General Theory of Crime, Stanford University Press, Stanford, Calif.

Gould, L. C. (1969). Who defines delinquency: A comparison of self-reported and officially reported indices of delinquency for three racial groups. Soc. Problems 16: 325-336.

Hindelang, M. J., Hirschi, T., and Weis, J. G. (1979). Correlates of delinquency: The illusion of discrepancy between self-report and official measures. Am. Sociol. Rev. 44: 999-1014.

Hindelang, M. J., Hirschi, T., and Weis, J. G. (1981). Measuring Delinquency, Sage, Beverly Hills, Calif.

Hirschi, T. (1969). Causes of Delinquency, University of California Press, Berkeley.

Jäger, J. (1984). Ethnic minorities and the police problems in Germany. In Brown, J. (ed.), Policing and Social Policy; The Cranfield-Wolfson Colloquium on Multi-ethnic Areas in Europe, Police Review Publication, London.

Junger, M. (1988). Racial discrimination in the Netherlands. Sociol. Soc. Res. 72: 211-216.

Junger, M. (1989a). Discrepancies between police and self-report data for Dutch racial minorities. Br. J. Criminol. 29: 273-284.

Junger, M. (1989b). Ethnic minorities, crime and public policy. In Hood, R. (ed.), Crime and Criminal Policy in Europe, Proceedings of a European colloquium, Centre for Criminological Research, University of Oxford, Oxford. 
Junger, M. (1990a). Delinquency and Ethnicity. An Investigation on Social Factors Relating to Delinquency Among Moroccan, Turkish, Surinamese and Dutch Boys, Kluwer Law and Taxation, Deventer.

Junger, M. (1990b). Studying ethnic minorities in relation to crime and police discrimination: Reply to Ben Bowling, Br. J. Criminol. 30: 493-502.

Junger, M., and Polder, W. (1991). Achtergronden van delinquent gedrag onder jongens uit etnische minderheden (Background of Delinquent Behaviour Among Boys from Ethnic Minorities), WODC, Gouda Quint bv., Arnhem.

Junger, M., and Zeilstra, M. (1989). Deviant gedrag en slachtofferschap onder jongens uit etnische minderheden (Deviant Behaviour and Victimization Among Youths from Ethnic Minorities). WODC, Gouda Quint bv., Arnhem.

Junger-Tas, J. (1985). Allochtonen in Nederland : een inleiding (Immigrants in the Netherlands: An introduction). Justitiële Verkenningen, pp. 1-33.

Kaufman, W. J., and Verbraeck, H. T. (1986). Marokkaan en verslaafd: een studie naar randgroepvorming, heröme gebruik en criminalisering (Moroccan and Addicted; A Study of Marginalization, Heroin Use and Crime), Afdeling Onderzoek ROVU, Gemeente Utrecht, Utrecht.

Maliepaard, R. (1985). Achtergronden van deviant gedrag bij allochtone jongeren (Background of Deviant Behaviour Among Immigrant Youth), Coordinatiecommissie Wetenschappelijk Onderzoek Kinderbescherming, Den Haag.

Merton, R. K. (1967). Social Theory and Social Structure, Collier-Macmillan, New York.

Mutsaers, M., and Boendermaker, L. (1990). Criminaliteitspreventie in het onderwijs (Crime Prevention at School), Ministerie van Justitie, WODC, K9, Den Haag.

Nadjaf Abrandabadi, A. H. (1983). L'évolution de la criminalté des étrangers en France. Rev. Peniten. Droit Pénal 2: 147-155.

Penninx, R. (1988). Minderheidsvorming en emancipatie; balans van kennisverwerving ten aanzien van immigranten en woonwagenbewoners (Minority Formation and Emancipation; An Evaluation of Knowledge with Respect to Immigrants and Caravan Dwellers), Samsom, Alphen a/d Rijn.

Reubsaet, T. J. M., Kropman, J. A., and van Mulier, L. M. (1982). Surinaamse migranten in Nederland, de positie van Surinamers in de Nederlandse samenleving (Surinamese Migrants in the Netherlands; The Position of the Surinamese in Dutch Society), Instituut voor Toegepaste Sociologie, Nijmegen.

Risvanoglu-Bilgin, S., Brouwer, L., and Priester, M. (1986). Verschillend als de vingers van één hand (As Different as the Fingers of One Hand), COMT, Rijksuniversiteit van Leiden, Leiden.

Rooduijn, M. J., and Latten, J. J. (1986). De leefsituatie van Turken en Marokkanen in Nederland (The Situation of Turks and Moroccans in the Netherlands), CBS-publikaties, Staatsuitgeverij, Den Haag.

Sampson, R. J. (1985). Race and criminal violence: A demographically disaggregated analysis of urban homicide. Crime Delinq. 31: 47-82.

Stevens, P., and Willis, C. F. (1979). Race, Crime and Arrests, Home Office Research Study No. 58 , HMSO, London.

Tennekes, J. (1989). Buitenlandse jongeren en cultuurconflict (Foreign youths and culture conflict). Migrantenstudies 5: 24-40.

Terlouw, G. J., and Suzanne, G. (1989). Een preventieproject in Gouda, eerste resultaten van een project voor Marokkaanse jongeren (A Prevention Project in Gouda, First Results of a Project for Moroccan Youth), WODC, Ministerie van Justitie, Den Haag.

Van den Berg-Eldering, L. (1981). Marokkaanse gezinnen in Nederland (Moroccan Families in the Netherlands), Samson, Alphen a/d Rijn,

Van der Erf, R. F. (1989). Beleidsrelevante migranten groepen demografisch gezien (Policy relevant migrants from a demographical point of view). Migrantenstudies 5:11-24.

van der Hoeven, E. (1986). De jeugdpolitie: een observatie-onderzoek (The Youth Police: An Observation Study), CWOK, Den Haag.

Werdmölder, H. (1985). Randgroepvorming: marginalisering en etnitisering onder Marokkaanse jongeren (Marginal groups: marginalization and ethnic revival among Moroccan boys). Mens Maatschappij 60: 142-161. 
Werdmölder, H. (1986). Van vriendenkring tot randgroep: Marokkaanse jongeren in een oude stadswijk (From Peer Group to Marginal Group: Moroccan Youths in an Old Neighborhood), Het Wereldvenster, Amsterdam.

WRR (Scientific Council for Government Policy) (1979). Etnische minderheden (Ethnic Minorities), WRR No. 17, Staatsuitgeverij, Den Haag. 